\title{
The Reflections on the General Teaching Strategies in New Standard College English Intensive Reading Classroom
}

\author{
Xin Wang \\ Changchun University of Science and Technology, China
}

\begin{abstract}
Based on the concepts of education reform, this paper elaborates the specific process of strategic performance in different language skill areas in New Standard College English intensive reading classroom. By concluding the reflections such as the "triple action" in metacognitive strategies and the grasp of the relationship between "supply" and "demand" in classroom teaching, we aim to explore some effective teaching strategies in College English teaching classroom.
\end{abstract}

Index Terms - teaching strategies, metacognitive strategies

\section{Specific Process of Strategic Performance in Different Language Skill Areas in NeW Standard College ENGLISH INTENSIVE READING CLASSROOM}

\section{A. Listening}

According to a large-scale study conducted by O'Malley et al.(1985), whether students can be successful listeners in class depends on their selection of effective strategies, such as selective attention, self-monitoring, elaboration by using background knowledge, and inferring the meaning of words or phrases from context. They also found that the more effective listeners used a more top-down approach, favoring inference and coherence detection strategies, instead of focusing on a word by word approach by using a bottom-up approach.

Take a part of listening passage from New Standard English book for example. This listening material is about an introduction to Oxford University and Cambridge University. Due to the fluent speed of the British speaker, it is obviously hard to grasp every word of the passage. So effective strategies are used by conducting students to focus on the key words such as location, dispute, boat race mentioned in questions. Meanwhile, students' attention span is limited. While listening, their self-monitoring ability will also be exercised by ignoring the so-called invalid information such as the time information, classification, differences of the two universities. Thus, the selective attention can be successfully achieved simultaneously. In this way, student's confidence in listening will be greatly boosted owing to their having no trouble at the seemly lengthy material.

\section{B. Speaking}

Oxford (1990) showed that the whole range of learning strategies may include memory, cognitive, compensation, metacognitive, affective, and social strategies. All of these will influence a learner's speaking skill development. In the process of oral English practice, no matter which strategies are adopted, to maximize the extension of time of students' staying in the conversation and provide the opportunity for their further communication is our basic concern.

1. Inviting strategy

As a teacher, we all dream one day that students' initiative can be developed fully and gone are the days that students are invited, asked, persuaded or begged to ask questions. It is the usual occurrence that after the teacher asks: "Is there a volunteer?" or "Who would like to say something?" Usually we will meet the situation that students are silent or respond with heads lowered. But there does exist some situation a few nervous students will glance at teachers, then lower their heads or sit up straight or murmur something to themselves. For experienced teachers, it is sign that they would like to express their ideas, but what they need is just a little encouragement. On this occasion, teachers should cultivate the quality of observation, that is to say, to be an observant person and keep watch for even the slightest response showed by students. So the questions such as "Maggie, would you like to say anything?" "Tony, do you agree with Maggie?" or "Susan, which answer do you agree more?" will be more welcomed than a simple, mechanic, flexible one to one asking pattern "What's your answer?" "How about you?". Because during the whole procedure of answering, the students are not only involved in the procedure of their understanding of the teacher's questions, but also the classroom activity of their focus on their classmates' performance. Thus their thinking scope is greatly widened and the answering material is enriched as well. This also has a "menacing" effect to the extent that the students will be more active in the classroom activity due to the fact they want to be the one nominated. Of course, we shouldn't ignore the volunteers' role, since the active and brave one's initiative can't be ruined by nominating shyer ones all the time. So it is also a good strategy to balance the frequency of asking for volunteers and nominating students since more students will 
be invited to the interactive classroom activity.

2. The tact strategy.

Oral English classroom is full of interactions of different sorts including student- student in English and Chinese. It is a common feeling shared by English learners that speaking in English creates a tension in them all the time due to cultural factors, linguistic factors and psychological or affective factors.

Sometimes during group work, when an activity is assigned and directions are explained, the students often do not start their discussion. It is a sign for the teachers that may be the students don't understand the directions clearly or they don't know where to start their speech. Naturally, teachers may make great efforts to explain the direction and procedure and they may usually ask simply "Do you understand?" to the whole class. More often, some students will feel too shy or shamed to say "I don't understand" in front of the whole class, so teachers generally can't receive an exact feedback from the students. To avoid this, the confirmative question "Is everything clear?" will be raised for individuals instead of the whole class. It is always better to go to each discussion group and ask them whether they have any problems or if anything is clear.

Another occasion often occurs in oral English classroom is that the students' mother tongue is used instead of the target language. For example, some students use their mother tongue to gossip, talking about things that are not related to the topic assigned. Some use their mother tongue as a communication strategy because they do not know how to express their ideas or a certain item in English, or when they cannot make themselves understood while using the target language. It is generally accepted to use limited mother tongue both by students and teachers. For example, when school begins after vacation, teachers tend to ask questions concerning vacation such as "How was your winter vacation going?" Answers from students may involve different feelings of what they experienced in the vacation. We should bear a tolerant idea towards the answer such as "I feel yumen during the winter vacation." Since there does exist some students who can't find an exact equivalence to express their true feeling in English, it is the teacher's task to guide the students to think in English, explain in English and finally introduce the most exact equivalence in English "depressed" or "morose". It is a process for students, especially poor spoken English students to correct their thinking and speaking habit and also a process for teachers to permit the limited use of mother tongue in order to reduce low level students' speaking tension and shyness.

3. The micro-skill training strategy.

In our oral English teaching practice, we usually pay much attention to the fulfillment of oral materials and the quantity of imparting instead of the real communication skills. It is generally understandable that students mainly focus on the understanding of oral materials, say, whether the words they know, the sentences they understand. It inevitably becomes an obstacle to the cultivation of students' spoken ability since they bear the idea in mind that they understand then they fulfill the teaching assignment. That is to say, what they understand is enough. In fact, teachers should input the idea of usage in class, that is no matter how simple the oral material is, even if all the words students are familiar with, if they can use it inflexibly, it means the failure of their mastery of oral practice.

Take Catching crabs in New Standard English for example. The theme of this unit is to discover yourself. So the questions such as When was your earliest memory? When was your happiest moment? which do you respect most: your character or your appearance? What's the nicest thing anyone has ever said to you? can be asked by students role playing as interviewers and interviewees in their mini-interviews. During the interview, ask-answer pattern can be employed and for the interviewers, they have to notice their partners' answers and spark more effective questions. Through such kind of classroom activity, students can be better informed that they needn't attend much to grammar nor pronunciation and without the use of correct words, students of similar linguistic background, a high degree of agreement can still be reached perfectly. Oral English practice aims at opening their mouths and sharing their thoughts freely.

\section{Reading}

A study conducted by Fischer and Mandl (2007) found that "good" readers were more flexible and adaptive who can clarify the task criteria and identify obstacles and difficulties more precisely, while "poor" readers were more oriented to text features than task requirements and use no concrete planning. Thus, the following strategies appeared to have positive effects on reading comprehension: summarizing in writing, underlining important parts, self-generated questions, checking to see if you can remember what you have read, asking questions about the bits you do not understand, taking notes, and imagining the story in your mind. In contrast, the following strategies were associated with negative results: thinking about something else while reading, writing down every word, skipping parts you do not understand, reading as fast as possible, saying words over and over, looking up words in a dictionary.

The passages in New Standard College English can be viewed as a series of reading materials in intensive reading classroom. Generally speaking, students tend to preview each unit by looking up new words in dictionaries instead of viewing them as a piece of comprehension materials to fulfill. Classroom reading are equal to their daily reading practice, since more skills are encouraged to be employed. If every passage we are going to learn is prepared as the source of our information, naturally, reading comprehension will not be our obstacle in English learning.

\section{Writing}

Writing is a highly complex thinking process which puts forward higher demands for one's cognitive ability, mind 
ability, language ability, organizing ability as well as self-monitor ability. Due to the complexity in language learning, the approach to writing practice should be attached much importance to.

When given a topic, it is customary for students to fulfill the task quickly without mulling over the frame of their writing, the phrasing of their languages. For all the various topics they practiced, little progress can they make. Ultimately, the problem lies in the regular thinking pattern. No matter how many times they practice, the sentences they use are still the simple active voice and the words they choose are still the one we learned in senior middle school or earlier. May be they have some creative ideas to express, but when thinking about the equivalent English words and phrases, still, they quit. Their failed attempts guide us to reconsider effective teaching strategies in English classroom. Thus, the strategy of targeted writing practice shows its particular superiority. If the writing assignment is required to include at least three new words and phrases we learned in class, one non-restrictive attributive clause, one sentence with passive voice, one word with different part of speech transformation, students' attention will be shifted correspondingly to the specific targets instead of aimless practice which indirectly enforces the professional skills of language uses.

Besides, other factors improving students' writing skills should also be considered:

1. Basic and advanced level writing teaching

As students' ability varies differently, when we are teaching in class, we will meet the challenges of making different standards for students inevitably. Following the requirement of syllabus, teachers' attention is mainly laid to train basic writing skills and cultivate language abilities as well.

According to students' language level, when setting the writing task, the teacher may bear the idea of tolerant measurement in mind. That is to say, for the low-level students, his writing aim is to define the specific writing field, apply the basic sentence structure to his writing and normalize his language usage. When it comes to the teacher's guidance, the standardized English writing pattern may be emphasized. May be it lacks critical thinking in the writing, but the basic mastery of language skills seems to be more important for the students at this level. Accordingly, teachers' measurement may ignore the critical thinking partially, and teacher may score it based on language standardization. Of course, it is just a matter of time. Not long after, students' awareness of language standardization will be promoted. Then the vocabulary and sentences in specific field may be given to apply to his writing. Soon after, they will get rid of the patterned writing and receive advanced level writing learning.

Whereas, for the high-level students, critical thinking will be widely welcomed. That is to say, different from the standard of low-level students, teachers should pay their attention to the writing content instead of its form such as whether the students can better integrate the elite words and sentences into his writing, whether the students can produce their creative and persuasive ideas, whether the specific vocabulary and sentences can be used properly in his writing. Thus, teachers' measurement should differ from the former. Their focus on content and process of writing should be laid at the first place owing to its features. They should hold a tolerant attitude towards students' minor mistakes. The most import thing is to judge the category of falseness and figure out the universal primary ones. It is unnecessary to tick every falseness on the paper, just group them into certain types and mark the name of falseness at the bottom of its paper. Thus, the students' initiative can be better improved and they will be cautious of the application of words and sentences.

2. The "model" effect

Model plays an essential role in writing teaching practice. Here, model doesn't only refer to the material, also the familiar individual among students. As we all know, Everyone needs certain degree of encouragement, especially students. If teachers use mild words to praise a student who behaves well in class, others may be positively influenced by their classmates' behavior. But in writing class, praise out of teachers' mouth is too mild compared with a copy of students' good writing paper. Among the writing papers handed in by students, we can select an excellent paper according to our teaching aim. The measurement of excellence is not limited to its quality, say, a high score writing paper. It depends on the writing skills we will impart in current class. That is to say, if today's writing skill is about coherence, students' writing papers with better cohesive devices will be picked as the model and the copy will be handed to the class. This will greatly encourage students' confidence in writing and stimulate their peers to create high level writing. Simultaneously, the model of writing papers can't be ignored. For the sake of a well formed organization, before starting a composition, teachers usually conduct the whole class to begin the writing procedures such as outlining, brainstorming, clustering as well. Through rounds of composition, students may practice their writing under their organization. Therefore, to present the writing sample is necessary in teaching procedure. As the limits of students' writing ability, their papers may not be perfect as the writing sample at most time. Via the comparison with the writing sample, the application of cohesive devices will be further enhanced and the excellent usage can be attempted in their own writing practice.

3. The situational writing practice

As the most effective English learning lies in learning in actual language situation which guarantees a large amount of receptive language information. English writing is no exception. While we set the writing task, we unavoidably are trapped in constructing writing simply with the type of argumentation forever. The ignorance of applied writing type and situational writing practice certainly ruins students' writing interest and categorizes directly English writing into the field of course instead of practice. Due to the test-oriented education, writing teaching mainly fails to meet the demand 
of language communication.

Situational writing practice originates from diary, the real things happen in everyone's life. It more concentrates on the description and narration of daily things such as doing chores. Just as a primary school student's writing paper, it demands the description of chores, working feeling, etc. Since it is a common practice every student experienced, it involves the students' mind activity of chores, such as preparing breakfast, washing dishes, cleaning up the house, doing laundry etc. The aim is to cultivate a good habit of writing, even though it is simply a procedure of recording. After all, it makes the students know the link between English usage and daily life. By using the vocabulary and phrases in specific situation, students can consolidate their language usage and cultivate a kind of awareness that when they are doing the usual things in life, they can connect the occasion with the proper English expressions.

4. The awareness of students' participation

No matter what taught by teachers, it is the students who fulfill the writing assignment. But the procedure can be designed as a mutual learning pattern which involves the lateral learning of students.

While writing papers with teachers' correcting returned to students, what arouse their interest is only score. This attitude prohibits the development of reception of writing skills. My practice is to divide students into several groups, and hand out papers written by students from group 1to group 2, group 2 to group 3 and so on until each group receives different papers written by others. This is group work, and surely each group deals with only one students' writing paper following the standards of writing assessment such as grammatical control, coherence, cohesion, organization of ideas, fluency of expression, mechanical skills, awareness of audience and use of vocabulary on the blackboard. After discussion, each group modifies the writing paper based on the standards above, and gives their possible suggestions on the paper. If time allowed, they may score each standard and give their own marks on others' paper. This practice indirectly helps students aware what they should notice while writing, motivates their initiative and facilitates obtaining more information and modification on their writing skills.

\section{The Reflections on the General Teaching StRategies In New Standard College English Intensive READING CLASSROOM}

My teaching experience in New Standard College English Intensive Reading Classroom inspires me with great imminency of the practice of students' participation and the subjective consciousness, what's more, the difficulty in transformation between teaching and learning, active and passive relationship. What we should often think, confer and research is the "eternal theme"--to make a better combination of the new text book and effective teaching strategies, to improve the quality of teaching based on the concept of teaching reform.

\section{A. The Embodiment of the "Triple Action" Principle in Metacognitive Strategies}

The cultivation of self-learning ability, via the way of metacognitive strategy training, can be achieved in the three principles of "initiative stimulation", "full-time interactive", "learning and practice linkage".

1. To stimulate students' initiatives and cultivate their personalized self-learning ability.

In the process of learning English, due to the differences between the students' individual knowledge structure, cognitive ability, learning level, it's liable to produce two extreme psychological tendencies of "contempt" and "awe": The former has a good mastery of language ability, confined to the stylized understanding of classroom content and neglecting the consolidation and learning expansion after class learning. Over time, the contemptuous psychology of "there is nothing to learn about College English" arises, resulting in the stagnant situation in English; the latter has relatively weak foundation in English and excludes input process in English learning. The way of passive learning leads to the pile up of language points in English knowledge, and gradually form the psychology of "fear of difficulty", finally, give up totally.

Both of the psychology is universal. To overcome it, it's teachers' responsibility to understand individual differences among students in language learning and help students set up their personalized self-planning and self-management card with daily learning drips roughly recorded. For better attention, they can be attached to the textbook to achieve the virtuous circle of self-monitor, self-assessment and self-incentive. Meanwhile, the implementation of a hierarchical teaching, say, the setting of graded quiz, in-class questions and homework, is also feasible for the independent choice of appropriate graded questions, which meets students' learning accomplishment to great extend.

2. Full-time interaction provides mutual platform in English learning.

Language learning has its own specificity. Restrictive of the factors such as text book, attending number, and lessons, it is unable to meet the different needs of students' learning, let alone to provide timely tracking counseling. Today, Prevailing in information technology, the network provides the best interactive platform for communication and expanding learning. It's a common practice for teachers to set up discussion groups on the net in the unit of classes. To help students develop their autonomy and sense of participation, students are encouraged to take turns regularly to screen, optimize network resources. During the whole process, teachers are acted as the role of background guidance, specifying different students to upload learning materials, exchange ideas regularly.

3. To create English "question- and- answer time" in bedroom by making the linkage between learning and practice.

Learning for practice is the purpose of English learning, but it is a prevailing truth that what we have learned is 
divorced from our application. The dumb English situation is going on for the disuse of the already learned vocabulary, grammar, sentence pattern.

It has become a habit for roommates to chat on bed before drifting to sleep and the topics involved are varied. For this phenomenon, the English "question-and-answer" time can be created. As we all know, learning needs atmosphere. The power of collectivism is unlimited. The leisurely air while chatting inevitably releases the rigid learning pattern, thus sets up a better way of learning. While one asking, the remaining answer, then the joint evaluation mode can be formed.

\section{B. The Grasp of "Supply And Demand" in Classroom Teaching}

The relationship between "supply and demand" in teaching and learning is reflected in two aspects: quantity and content. College English series courses have the common features of wide knowledge and cultural points coverage. Obviously, it is impossible for teachers to impart all-embracing knowledge mentioned in text books with the limited time. Then it comes to the question of adoption and discard. Strategic trade-off is a rational choice made by teachers based on students' practical needs. After all, the more knowledge teachers impart is not equal to the better their students learn. To guide students to learn more, to see more and think more is what the teachers should do, since the students are grown-ups. Therefore, in the actual teaching, more attention should be paid to the balance between language knowledge explanation, skills training and the allocation proportion of other imparted knowledge. Besides, to strengthen the penetration of cultural awareness and cultivation of diverse mindset, to set more real-life scenarios for students' language practice and language skills training with cognitive and emotional characteristics is also a feasible attempt in teaching practice in the future.

\section{CONCLUSION}

Through elaborating the specific process of strategic performance in different language skill areas in New Standard College English intensive reading classroom, we make some reflections on classroom teaching practice. By exploring the effective strategies characterized both by textbook and university in classroom teaching, we aim to master the accumulation of first-hand experience in teaching for better grasping the textbook content and adaption to the education reform trends.

\section{REFERENCES}

[1] Arthur Hughes. (1989). Testing for Language Teachers. Beijing: Foreign Language Teaching and Research Press.

[2] Cameron Deboran. (2001). Working with Spoken Discourse. London: SAGE publication

[3] Heaton, J.B. (1988). Writing English Language Tests. Beijing: Foreign Language Teaching and Research Press.

[4] Jiang Jingyang. (2006).Communicative Activities in EFL Classrooms, Hangzhou: Zhejiang University Press.

[5] Rao Zhenhui. (2007). Individual Differences and Cultural Factors, Shanghai: Shanghai Foreign Language Education Press.

[6] Cheng Xiaotang \& Zheng Min. (2002). English Learning Strategies. Beijing: Foreign language teaching and research Press.

[7] Huang Guowen. (2003). Summary of Discourse Analysis.Changsha: Hunan Education Press.

[8] Hu Wenzhong. (2006). College basic English,Teaching. Beijing: Foreign Language Teaching and Research Press.

[9] Jiang Jingyang. (2006). Research on Foreign Language Classroom Communications. Hanzhou: Zhejiang University Press.

[10] Liu Xuxiang. (2010). Research on the Implementation of present teaching strategies in high school English class .Southwestern University. http://wenku.baidu.com/view/a3816e70f242336cleb95ea9.html.(accessed 29/8/2012).

[11] Wang Duqin. (2002). On English Teaching Strategies. Beijing: Foreign Language Teaching Research Press.

[12] Zhang Liguang. (2003). On English writing Teaching from students' writing performance. Teachers English teaching and research, 2, 17-18.

[13] Zhu Xiaoyan. (2011). English Teaching Strategies - How to Select and Apply Effectively. Shanghai: Shanghai Foreign Language Education Press.

Xin Wang was born in Changchun, China in 1981. She received his master degree in linguistics from Changchun University of Science and Technology, China in 2006.

She is currently a lecturer in the School of Foreign Languages, Changchun University of Science and Technology, China. Her research interests include pragmatics and literature. 